\title{
A Study of HIV Infection Pattern in Clients Attending Integrated Testing and Counselling Center in Most Backward District of India
}

\author{
Pratibha Mane and Jyoti Sangwan* \\ Department of Microbiology, SHKM GMC, Nalhar, NUH, India \\ *Corresponding author
}

\begin{tabular}{|l|}
\hline K e y w o r d s \\
ICTC, Heterosexual \\
Transmission, HIV, \\
NACO
\end{tabular}

\section{A B S T R A C T}

India has a burden of 2.5 million people infected with HIV making it the third largest HIV epidemic in the world after Africa and Nigeria. India contributes to almost $60 \%$ of South Asia's HIV epidemic. HIV is an epidemic which is affected by various factors like demography, socio- cultural behavior, economic background etc. The integrated counseling and testing centers (ICTC) were formulated by national AIDS control organization (NACO). These are functioning in various hospitals providing a first interface between the client and public health system and have great deal of impact on modifying risk behavior of general population if utilized properly. To know pattern of HIV infection in ICTC center of a tertiary care teaching hospital. HIV testing was done as per NACO guidelines. Maximum sero reactivity was found in 25-34 years of age group followed by 35-49 years age group. Heterosexual transmission was the major route of transmission followed by parent to child transmission. Out of 34781 clients tested for HIV infection, 111 were found HIV I seropositive and only one was HIV II seropositive. Seropositivity was higher in male clients 59 than in females 52. Recently the National Institution for Transforming India (NITI Aayog) rated Mewat (Nuh) district of Haryana as the most backward district of India. Thus, extreme poverty, social taboo, illiteracy is the important reasons for the underutilization of the services. There is dire need for intervention to clear these hindering factors so that these services are effectively utilized.

\section{Introduction}

As per joint united nations programme on HIV/AIDS (UNAIDS) in 2012, HIV infection is reported worldwide, with 34.2 million people are living with HIV and AIDS (UNAIDS report \& NACO annual report). India has a burden of 2.5 million people infected with HIV making it the third largest HIV epidemic in the world after Africa and Nigeria (Sherwal et al., 2015). India contributes to almost $60 \%$ of South Asia's HIV epidemic (Moses et al, 2006 and Ganju et al., 2014).

According to GAP India factsheet of CDC, there is $50 \%$ decline in new annual HIV infections with 0.12 million cases in 2009 from 0.27 million cases in 2000 . Though this is not a uniform phenomenon with slight increase in number of cases in low prevalent states. There is no uniformity in the data of 
HIV infection and its distribution in the country.

The integrated counseling and testing centers (ICTC) were formulated by national AIDS control organization (NACO). These are functioning in various hospitals providing a first interface between the client and public health system. The number of ICTC centers is ever increasing thus providing greater platform to avail these services. These centers provide confidential testing for HIV infection and counselling. Even though these services are expanding rapidly only $10-20 \%$ of the infected persons know their HIV status. There is wide variation in the utilization of these services in different parts of the country. The various factors which contribute for this includes urban or rural areas, social taboos, level of education, socioeconomic status, availability and distance of healthcare facility. The acceptability of utilizing these facilities is usually higher in urban areas and in educated peoples. The rapid to and fro movement of population from rural to urban areas in search of livelihood has created many complex situations. This has brought the epidemic of HIV spread in rural areas with a rapid rate (Ganju et al., 2014).

These services are expected to be availed by the clients who are willing to get tested due to their high-risk behavior. These services can also be availed by the persons who are coming to healthcare facilities for other services and they are advised for HIV testing by the treating clinician. This group is called provider initiated. The various ICTC centers get different proportions these two-group depending upon the area and population it serves.

Data generated in ICTC may provide important clues to study the prevalence of HIV infection. Socio-demographic and epidemiological distribution of HIV seropositive patients can also be studied by analyzing these data.

This study was planned to know the pattern of HIV infection in ICTC center of a tertiary care teaching hospital.

\section{Materials and Methods}

This was a cross sectional descriptive study of clients availing facilities of ICTC center in a medical college in Nuh district of Haryana. The data was collected from January 2014 to December 2016. All clients referred from various departments were included in the study. All the clients attending the ICTC were counseled by counselor and written consent was taken. The data pertaining to the clients including name, age, sex, occupation, education, marital status, risk factor associated were documented in the register. A unique PID number was given and $3-5 \mathrm{ml}$ blood sample was collected. HIV testing was done as per NACO guidelines with the rapid test kits provided by HSACS/NACO. The first test kit was of highest sensitivity. The second and third kit were of high specificity. Therefore, when the test with first test kit is nonreactive, second and third tests were not done. The result was nonreactive for that sample. If the first test was reactive, then second and third tests were performed. If all the tests were reactive, then the sample was reported as reactive. Posttest counselling was also done as per standard protocol.

\section{Results and Discussion}

The number of clients who availed ICTC facilities during 36 months was 34781. All clients were provider initiated. It was observed that total number of clients attended the ICTC has increased every year, however the HIV positivity decreased from $0.4 \%$ in 2014 and $0.2 \% 2016$ (Figure 1). Maximum seroreactivity was found in 25-34 years of age 
group (41\%) followed by $35-49$ years age group (33\%). Heterosexual transmission was the major route of transmission (84\%) followed by parent to child transmission $(5.4 \%)$ as shown in table -3 . Out of 34781 clients tested for HIV infection, $111(0.31 \%)$ were found HIV I seropositive and only one was HIV II seropositive (0.002\%). Seropositivity was higher in male clients 59 $(53 \%)$ than in females 52 (46 \%). Heterosexual transmission was the major route of transmission.

The present study has documented the prevalence, possible mode of transmission of HIV infection among all the clients attending ICTC. This center is situated in tertiary care teaching hospital. The institute provides hospital facilities to the one of the most backward areas of the country. Many peoples don't have access to health care apart from this hospital in their nearby areas. This observational study might give important insights into the trend of peoples availing the healthcare facilities and may prove important in further modification of the planning of facilities (Table 1-3).

Table.1 Prevalence of HIV from year 2014-2016

\begin{tabular}{|l|l|l|l|}
\hline Year & Number & Nonreactive & Reactive (\%) \\
\hline $\mathbf{2 0 1 4}$ & 10745 & 10699 & $46(0.4 \%)$ \\
\hline $\mathbf{2 0 1 5}$ & 11204 & 11169 & $35(0.3 \%)$ \\
\hline $\mathbf{2 0 1 6}$ & 12832 & 12802 & $30(0.2 \%)$ \\
\hline Total & 34781 & 34670 & $111(0.3 \%)$ \\
\hline
\end{tabular}

Table.2 Age wise distribution of seropositive clients

\begin{tabular}{|l|c|c|c|c|c|}
\hline \multirow{2}{*}{ Year } & \multicolumn{5}{|c|}{ Age in years } \\
\cline { 2 - 6 } & $0-14$ & $15-24$ & $25-34$ & $35-49$ & $\geq 50$ \\
\hline $\mathbf{2 0 1 4}$ & 4 & 6 & 16 & 16 & 5 \\
\hline $\mathbf{2 0 1 5}$ & 4 & 1 & 14 & 11 & 4 \\
\hline $\mathbf{2 0 1 6}$ & 3 & 1 & 16 & 10 & 0 \\
\hline Total & 11 & 8 & 46 & 37 & 9 \\
\hline
\end{tabular}

Table.3 Route of transmission in the HIV reactive patients

\begin{tabular}{|l|c|c|c|c|c|c|c|c|}
\hline \multirow{2}{*}{ Year } & \multicolumn{3}{|c|}{ Heterosexual } & \multicolumn{2}{c|}{$\begin{array}{c}\text { Through blood } \\
\text { and blood product }\end{array}$} & \multicolumn{2}{c|}{ Mother to child } & \multicolumn{2}{c|}{ Unknown } \\
\cline { 2 - 10 } & Male & Female & Male & Female & Male & Female & Male & Female \\
\hline $\mathbf{2 0 1 4}$ & 21 & 19 & 0 & 2 & 1 & 1 & 1 & 1 \\
\hline $\mathbf{2 0 1 5}$ & 21 & 8 & 0 & 2 & 2 & 0 & 1 & 1 \\
\hline $\mathbf{2 0 1 6}$ & 12 & 13 & 1 & 1 & 1 & 1 & 0 & 1 \\
\hline Total & 54 & 40 & 1 & 5 & 4 & 2 & 2 & 3 \\
\hline
\end{tabular}


Fig.1 Seroprevalence of HIV clients

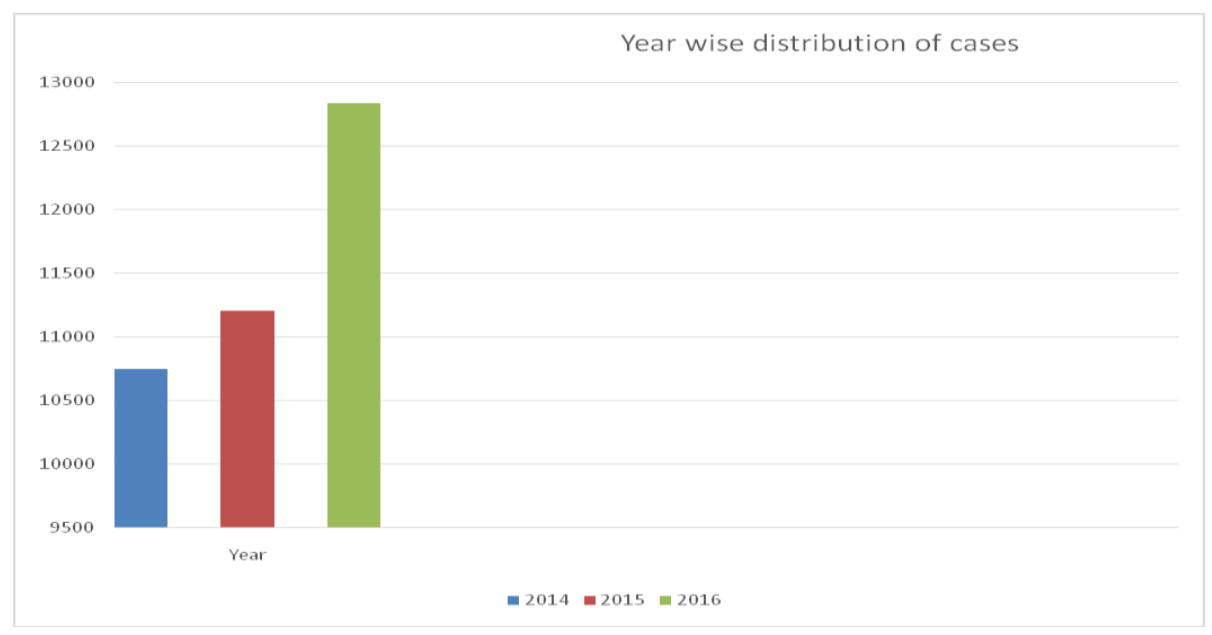

The number of clients went on increasing in each year in our study. This was probably due to increased confidence of the clients in facility. Intense health education and awareness campaign coupled with pretest counseling brought the positive response which resulted in increase in number of clients using the facility.

According to AIDS Factsheet Haryana, the prevalence of HIV infection varies in Indian states, Haryana is one of the states with very low prevalence rate of $0.19 \%$. There is changing pattern in prevalence rates in different groups who are availing the ICTC facilities.

In our study percentage of females affected were less, similar finding observed with other studies done by Gupta, Madkar and Sherwal et al., in 2007, 2011 and 2014 respectively.

The analysis of the reactive group when they were divided in different age groups showed interesting findings. As per NACO data, dominant age group which is seropositive is 25 - 34 years accounting for $82.4 \%$. As expected this age group is more sexually active and more prone for HIV infection (NACO Factsheet). We have found in our study that seropositivity was $41 \%$ in age group of $25-34$ years and $33 \%$ in $35-49$ years group which is reverse finding to other studies (Gupta et al., 2007 and Madkar et al., 2011). This might be due to early marriages in this region and this is child bearing age and there is increased risk of parent to child transmission.

In India the predominant subtype for infection is HIV - I, however the first case report of HIV - II infection was reported in 1991. After that there are many case reports reporting infection by HIV - II from the country. Various studies published afterwards show prevalence of HIV - II to be in the range of 0.13 to $1.8 \%$ from south India. Studies from Delhi, Pune and Jaipur which are in north India show $0.13 \%$ of seropositivity (Kashyap et al., 2011, Tadokar et al., 2013 and Sabharwal et al., 2015). We have found a single positive case for HIV - II $(0.002 \%)$, none of these reactive for both HIV - I and HIV - II.

In our study, heterosexual unprotected contact was the commonest mode of transmission of HIV followed by parent to child. We have found the similar trend exists in many of the other Indian studies (Gupta et al., 2007) and (Kommula et al., 2012). All the seroreactive patients were referred for antiretroviral 
therapy, care and management. Recently The National Institution for Transforming India (NITI Aayog) rated Mewat (Nuh) district of Haryana as the most backward district of India.9 NITI Ayog Report, 2018). There is very low level of literacy, low per capita income, less opportunities for employment. There are many social taboos which includes not approaching the healthcare facilities even in serious medical ailments. Self-stigma and fear of discrimination are central to individuals not seeking HIV tests and treatment. In our study all the clients who came to ICTC were initiator provided. No one voluntarily attended ICTC, indicating lack of awareness of HIV and ICTC. It is extremely important to increase awareness by repeated health education programmes and make it more acceptable by integration of ICTC into various community organizations.

Thus, extreme poverty, social taboo, illiteracy are the important hindrance for the underutilization of the services. There is need for intervention to clear these hindrance factors so that these services are effectively utilized.

\section{Limitations of the study}

The study is based on data collection and reporting by counselors employed in ICTC and need not be a real presentation of community. Further studies which involves direct data collection from community is required.

\section{References}

Ashok Kumar. Nuh at bottom of NitiAayogs 101 most backward districts. 0204.2018. THE HINDU [Accessed from https://www.thehindu.com/news/cities/ Delhi/nuh-at-bottom-of-niti-aayogs101-most-backward- districts/article23409464. Last assessed 2018 August 15.

Department of AIDS control. Ministry of health and family welfare, government of India. District HIV/AIDS epidemiological profiles developed through data triangulations factsheet Haryana. November 2013.

Ganju SA, Bhagra S, Kanga AK, Singh DV, Chauhan R. Eleven-year performance of an Integrated Counseling and Testing Center in a tertiary care hospital in Himachal Pradesh, India. CHRISMED J Health Res 2014; 1:134-9.

Gomes LA, Somu G, Rinkoo AV, Vinay GM. Utilization of integrated counseling and testing centre (ICTC): A comparative study between a tertiary care teaching hospital and a government district hospital in Karnataka. Indian J Public Health 2007; 51:39 40.

Gupta, V., Singla, N., Lehl, SS., Chander, J. Clinicoepidemiological profile of HIV infection over a period of six years in a North Indian tertiary care hospital. Indian J Med Microbiol 2007; 25: 171.

HHS/CDC Global AIDS program (GAP) in India. The GAP India Factsheet. Available from: http://www.Cdc.gov/nchstp/od/gap/cou nties/ India.htm [Last accessed 2013 Jun 20].

Kashyap B, Gautam H, Bhalla P. Epidemiology and seroprevalence of human immunodeficiency virus type 2 . Intervirology 2011; 54:151-5.

Kommula, V.M., Mishra, A.K., Kusneniwar, G.N., Chappa, S.N., Raghava Rao, K.V. Profile of HIV positive clients in an ICTC of a private medical college, Andhra Pradesh: A situational analysis. NJIRM 2012; 3(2): 36-40.

Madkar, S.S, Nilekar, S.L, Vankudre, A.J. Prevalence of HIV infection among persons attending integrated counceling and testing centre, Ambajogai. National 
Journal of Community Medicine 2011; 2(2): 213-215.

Moses, S., Blanchard, J.F., Kang, H., et al. (2006) AIDS in South Asia: Understanding and Responding to a Heterogeneous Epidemic. The World Bank, Washington DC, 7-19. http://dx.doi.org/10.1596/978-0-82136757-5

Murugan S, Anburajan R. Prevalence of HIV2 infection in South Tamil Nadu. Indian J Sex Transm Dis 2007; 28: 113.

National AIDS Control Organization, Ministry of Health and family welfare, Government of India. Annual Report 2011-2012.

National AIDS Control Organization, Ministry of Health and family welfare, Government of India. India factsheet 2012.

Sabharwal E R. Four year data from an ICTC of a tertiary care hospital in Jaipur, Rajasthan. Indian J Med Microbiol 2015; 33: 187-9

Sherwal, B.L., Gupta, P., Nayak, R., Gogoi, S., Suri, S. and Dutta, R. Prevalence of HIV in a Tertiary Care Centre in Delhi: A Five-Year ICTC Based Study. World Journal of AIDS, 2015;5: 1-9.

Steinbrook R. HIV in India a complex epidemic. N Engl J Med 2007; 356: 1089-93.

Tadokar VS, Kavathekar MS. Seroprevalence of human immunodeficiency virus type 2 infection from a tertiary care hospital in Pune, Maharashtra: A 2 year study. Indian J Med Microbiol 2013; 31: 3145.

Together we will end AIDS. Joint United Nation Programme on HIV/AIDS (UNAIDS). 2012.

\section{How to cite this article:}

Pratibha Mane and Jyoti Sangwan. 2020. A Study of HIV Infection Pattern in Clients Attending Integrated Testing and Counselling Center in Most Backward District of India. Int.J.Curr.Microbiol.App.Sci. 9(09): 2244-2249. doi: https://doi.org/10.20546/ijcmas.2020.909.279 